One Year Term Review as a Participating Guest in the Detonator and Detonation Physics Group

A. Lefrancois, F. Roeske, T. Tran, R. S. Lee

February 15, 2006 
This document was prepared as an account of work sponsored by an agency of the United States Government. Neither the United States Government nor the University of California nor any of their employees, makes any warranty, express or implied, or assumes any legal liability or responsibility for the accuracy, completeness, or usefulness of any information, apparatus, product, or process disclosed, or represents that its use would not infringe privately owned rights. Reference herein to any specific commercial product, process, or service by trade name, trademark, manufacturer, or otherwise, does not necessarily constitute or imply its endorsement, recommendation, or favoring by the United States Government or the University of California. The views and opinions of authors expressed herein do not necessarily state or reflect those of the United States Government or the University of California, and shall not be used for advertising or product endorsement purposes.

This work was performed under the auspices of the U.S. Department of Energy by University of California, Lawrence Livermore National Laboratory under Contract W-7405-Eng-48. 


\title{
ONE YEAR TERM REVIEW AS A PARTICIPATING GUEST IN THE DETONATOR AND DETONATION PHYSICS GROUP
}

\author{
A.Lefrancois (*), F.Roeske, T.Tran, R.S.Lee \\ Energetic Materials Center, Lawrence Livermore National Laboratory, Livermore, \\ CA 94550 - USA \\ ${ }^{(*)}$ Participating guest at LLNL from DGA/Centre d'etudes de Gramat - France
}

The one year stay was possible after a long administrative process, because of the fact that this was the first participating guest of $\mathrm{B}$ division as a foreign national in HEAF (High Explosives Application Facility) with the Detonator/Detonation Physics Group.

\subsection{DETONATOR/DETONATION PHYSICS GROUP}

The mission on the Detonator/Detonation Physics Group is to:

- Develop new detonator technology, as needed

- Support B-Program HE firing activities

- Support existing stockpile initiation systems

- Improve understanding of the physics of HE initiation

- Maintain and improve diagnostic capability for detonators/boosters

- Maintain and improve modeling capability for detonators/boosters

The scope of the mission includes the following tasks: 
- Perform research and advanced development on high-explosive initiation trains. materials.

- Perform experiments to characterize high explosives and other energetic

- Perform experiments to study the interaction of reacting HE or energetic materials with inert materials.

- Design, develop, build and operate high-voltage capacitor discharge systems.

- Design, develop, build and execute experiments and tests involving high explosives assemblies, and capacitor discharge systems, using advanced diagnostic equipment.

- Design, develop, build and operate lasers and optical systems and use them in experiments involving shock waves and high explosives.

- Design, develop, build and operate laser systems and use them in machining and surface treatment of high explosives, inert materials, and assemblies containing high explosives

- Perform maintenance and repair operations on equipment for which the Group and B Program are responsible, as appropriate. This includes bringing in qualified field maintenance personnel from equipment manufacturers for troubleshooting or specialized maintenance.

The work is performed in Building 191 (HEAF). Almost all of these activities involve some degree of hazard, the principal hazards being from energetic materials (including HE), high voltage and intense laser light. The mitigation and control of these hazards will be addressed.

\subsection{EXPERIMENTS}

Thanks to the approval to work in HEAF with the group, it was possible to attempt some of the experiments they are doing, and discuss the experimental set-up, and metrology :

- Laser femtosecond safely machining of HE parts, and detonators [1][2][3]

- Corner turning test with initiating HE

- Assessment EBW, of the Explosive Bridge wire experiments in water[4]

- Using diode as a shock time arrival metrology [5] 
- HDV Heterodyn Doppler Velocimeter [6]

\subsection{NUMERICAL SIMULATIONS}

Thanks to two courses at LSTC and the LLNL clusters access, it was possible to perform numerical simulations in 2D and 3D using LS-Dyna single processor and multiprocessors versions. Different kinds of simulations were performed to help in the design of new set-ups, to compare experiments and simulations and to test the new electromagnetism package as a beta tester. The different subjects are listed below :

- Shock desensitization effect in the stanag 4363 confined explosive component water gap test (ECWGT) for components having a diameter less than $5 \mathrm{~mm}$ [7][8][9]

- Diameter effect experiments in initiating explosives [10]

- Floret test, comparison between experiments and simulations of the dent,[11]

- Small scale cylinder test with a groove, comparison between experiments and calculations [12]

- Shock arrival time metrology using photo-diode, numerical simulations[13]

- Corner turning test with initiating HE

- Thermal analysis

- Low impact velocity safety test

- Isentropic compression up to 200 kbars for LX 04, Numerical simulations and Comparison with Z-accelerator experiment shot 1067 [14]

- Isentropic compression for TATB based HE samples, numerical simulations and comparison with Z-accelerator experiment shot 1967 [15]

- Isentropic compression with a rectangular configuration for Tungstene and Tantalum, computations and comparison with Z-accelerator experiments shots 1511 and 1555 [16]

- Copper tube compression in Z-current geometry, numerical simulations and comparison with Cyclope experiments [17]

- Isentropic compression in a strip line, numerical simulations and comparison with GEPI shot 268 [18] 


\subsection{ATTENDED LECTURES IN OTHER FIELDS}

It was also possible to attempt many lectures in other fields [19]:

- Inertial confinement fusion ablator application

- Nuclear Science

- Crystal Defects

- Phase Transition

- Binder

- Biosensing

- Nanotechnology

- Mechanical and thermal properties

- Metrology

\section{$1.5 \quad \underline{\text { VISITS }}$}

Many visits were organized:

- HEAF, High Explosives Application Facility

- $\quad$ DAC, Diamond Anvil Cell

- $\quad$ Femtosecond laser safely HE machinig

- Micro-detonics laboratory

- $\quad$ Visite du NIF National Ignition Facility

- RISI, detonator company, EBW (Exploding Bridge Wire), EFI (Explosive Foil Initiator)

- $\quad$ LIGA foundry, microsystems manufacturing

- Accelerator for Mass Spectroscopy (negative ion source for 14 C analysis) 


\subsection{FUTURE PLANS, INTERACTIONS, AND POSSIBLE COOPERATIONS}

Some future possible interactions are listed below:

- Safely machining the HE with the femto-second laser

- High current machine, experiments and modeling : Z ICE experiments, French machines

- Experiments and simulations of the dent for LLM 105 in the Floret test

- Diameter effects in initiating HE

- Metrology, velocity measurement, shock arrival time metrology with photodiode

- Gas gun experiments, thermal properties interaction with run to distance detonation

\subsection{ACKNOWLEDGEMENT}

The authors would like to thank Karen Ballou for her continuous support. Helpful and fruitful discussions with the group and people from HEAF, EMC, CMS and B-division are gratefully acknowledged. Thank you all for making that possible.

* This Work has been performed under the auspices of the U.S. Department of Energy by the Lawrence Livermore National Laboratory under Contract W-7405-Eng-48.

\subsection{REFERENCES}

[1] F.Roeske, J.Benterou, R.Lee, E.Roos, Cutting and Machining Energetic Materials with a Femtosecond Laser, PEP December 2002

[2] E.Roos, J.Benterou, R.Lee, F.Roeske, B.Stuart, Femtosecond Laser Interaction with Energetic Materials, SPIE's International Symposium High-Power Laser Ablation April 2002

[3] J.Benterou, F.Roeske, P.Wilkins, K.Carpenter, Safety Guidelines for Laser Illumination on Exposed High Explosives and Metals in Contact with HE with Calculation Results, 29th International Pyrotechnic Seminar, 2002

[4] P.R.Wilkins, A.M.Frank, R.S.Lee, C.May, Dynamic Shock Front Measurements and Electrical Modeling of the Exploding Gold Bridge Wire in a Detonator, Europyro Saint Malo 2003 
[5] P.Wilkins, The Optical and Electrical Effects of Direct Bandgap Semiconductor Junctions under Explosive Shock, International Detonation Symposium, 2006

[6] O.T.Strand, L.V.Berzins, D.R.Goosman, W.W.Kuhlow, P.D.Sargis, T.L.Whitworth, Velocimetry Using Heterodyne Techniques, August 2004, Alexandria, VA, US

[7] A.S.Lefrancois, R.S.Lee and C.M.Tarver, Shock Desensitization Effect In The Stanag 4363 Confined Explosive Component Water Gap Test (ECWGT) For Components Having A Diameter Less Than $5 \mathrm{~mm}$, submitted at the Detonation Symposium 2006

[8] C.M.Tarver, A.Lefrancois, R.S.Lee, K.Vandersall, Shock Initiation of the PETNbased Explosive LX-16, proposed at the $13^{\text {th }}$ International Detonation Symposium, Norfolk, VA, July 23-28, 2006

[9] A.S.Lefrancois, F.Roeske, J.Benterrou, C.M.Tarver, R.S.Lee, B.Hanna, Ability Of The Confined Explosive Component Water Gap Test (ECWGT) Defined In The Stanag 4363 To Assess The Shock Sensitivity Of Mm-Scale Detonators, proposition for the Fuze conference 2007

[10] A.Lefrancois, J.Benterou, F.Roeske, Ed Roos, Diameter Effect Experiments In Initiating Explosives, LLNL report, Feb.2006

[11] A.Lefrancois, F.Gagliardi, J.Cutting, T.Tran, Floret Test, Comparison between Experiments and Simulations of the Dent , LLNL report, Feb.2006

[12] A.Lefrancois, F.Gagliardi, E.Lee, T.Tran, F.Roeske, Small Scale Cylinder Test with a Groove, comparison between experiments and calculations, LLNL report, Feb.2006

[13] A.Lefrancois, P.Wilkins, Shock Arrival Time Metrology using Photo-diode, numerical simulations, LLNL report, Feb.2006

[14] A.Lefrancois, D.Hare and P.L'Eplattenier, M.Burger, Isentropic Compression up to 200 kbars for LX 04, Numerical simulations and Comparison with experiments LLNL report, Feb.2006

[15] A.Lefrancois, K.Vandersall and P.L'Eplattenier, M.Burger, Isentropic Compression For Tatb Based He Samples, Numerical Simulations And Comparison With Experiments, LLNL report, Feb.2006

[16] A.Lefrancois, D.B.Reisman, M.Bastea and P.L’Eplattenier, M.Burger, Isentropic Compression With A Rectangular Configuration For Tungstene And Tantalum, Computations And Comparison With Experiments, LLNL report, Feb.2006 
[17] A.Lefrancois and P.L'Eplattenier, M.Burger, Copper tube compression in Zcurrent geometry, numerical simulations and comparison with Cyclope experiments, LLNL report, Feb.2006

[18] A.Lefrancois and P.L'Eplattenier, M.Burger, Isentropic Compression In A Strip Line, Numerical Simulations And Comparison With Gepi Shot 268, LLNL report, Feb.2006

[19] Attended lectures in other fields 